\title{
Literatures Review on Transaction Costs Measurement Advances
}

\author{
Zhengchao Lv ${ }^{1}$, Qin Liu ${ }^{1} \&$ Pan Wang ${ }^{1}$ \\ ${ }^{1}$ Management School, University of Shanghai for Science and Technology, Shanghai, China \\ Correspondence: Zhengchao Lv, Management School, University of Shanghai for Science and Technology, 334\# \\ Jungong Road, Shanghai, China. E-mail: 1vzhengchao2009@126.com
}

Received: June 19, 2012 Accepted: July 10, 2012 Online Published: September 20, 2012

doi:10.5539/ass.v8n12p127 URL: http://dx.doi.org/10.5539/ass.v8n12p127

\begin{abstract}
Theory of transaction costs and its measurement has been regarded as the focus since its being put forward by scholars. Additionally, researches on the measurement are relatively less in China. This paper devotes to reviewing and analyzing present advanced methodologies of transaction costs measurement. And it summarizes the difficulties of measurement based on the concept of transaction costs. Furthermore, it introduces three difficulties of measuring. They are unclear definition of transaction costs, unobservable costs in non-market and the unable replacement of opportunity costs. It concludes the measuring methods both on the macro and micro aspects. On macro aspect, it introduces methods as direct measuring, model-built measuring and margin analysis measuring. On micro aspect, it introduces methods as buy-sale price margin, typical reference quantities method, investigating method and data statistics method.
\end{abstract}

Keywords: transaction costs, measurement, reviews

\section{Introduction}

Transaction costs have been important for modern economics, especially significant for studying institution system and social structure transformation, since Ronald H. Coase (1937) proposed it. Transaction costs affects economics system operation radically, for example, they effects what should be produced and what kind of exchanges would happen in the market; they effects what organization could exist and what kind of game rule could continue (Alexandra Behnam \& Lee Behnam, 2003). "Transaction costs" — the costs of making exchanges _ - has become more important in explaining the structure of market and nonmarket forms of economic organization (Coase 1937, 1960; Wallis \& North, 1986).

On macro aspect, transaction costs which widely exist have become a key indicator for studying economics system operation. It is a major factor for reducing costs and improving performance. The whole institution economics will be more believable if the transaction costs could be measured. The transformation from the state-planned economy to market-oriented economy can't be accomplished in an action, but can be evaluated step by step. At present, the phenomenon of both economics system - planned and market-oriented coexistence will persist in long period in China. During the metabolism progress of institutions transformations, transaction costs, the core of new institution economics seems to be particularly important. It is an unavoidable topic when studying social structure reform and institution evolution. On the micro aspect, transaction behaviors which can increase transaction costs, such as opportunism behavior, exist among enterprises and economic activities widely. An appropriate governing method is aimed at reducing the costs caused by transaction behaviors. In order to examining an effective method of governing transaction behaviors, the quantity of transaction costs should be estimated. So studying measuring methods of transaction costs is necessary.

So far various measuring methods have been applied by scholars, but there is few consolidated studying for the measuring methods. This literature review attempts to introducing some significant measuring methods for further study reference.

\section{Transaction \& Transaction Costs}

\subsection{Definition of Transaction}

Scholars have different ideas about the definition of transaction in different periods. For example, John R. Commons (1931) came up with a generalized concept about transaction before Coase's literature "The Nature of the Firm" has been published. According to Commons, transactions are just the transfer and obtain of object 
future ownership between two persons, and the substance of transaction is the ownership transfer, not the object itself moves from one to another. A transaction occurs when a good or a service is transferred across a technologically separable interface, one stage of activity terminates and another begins (Oliver E. Williamson, 1981). It is generally stated that, transaction is just the exchange of goods or service by the medium of currency. But to a narrow definition, transaction is an activity of buying or selling objects or interests among people; and to a universal definition, all the activities among enterprises, persons, enterprise and person can be named as transaction.

\subsection{Definition of Transaction Costs}

The idea of transaction costs origin from Coase's literature-The Nature of the Firm. In The Problem of Social Cost, he indicates that in order to carry out a market transaction it is necessary to discover who it is that one wishes to deal with, to inform people that one wishes to deal with and to what terms, to conduct negotiations leading up to a bargain, to draw up the contract, to undertake the inspection needed to make sure that the terms of the contract are being observed, and so on (Coase, 1960). Though, numbers of economists devotes to researching and improving the theory of transaction costs but they haven't unified conclusion. For instance, Coase (1937) explains it as the cost of using price mechanism, Williamson regards it as the cost and expenses of economics system operation (Liu \& Shen, 2006). And Steven Cheung (1998) deems that the transaction costs indicate all the costs, besides physical processes of production and transportation. Various definitions about transaction costs have led to the difficulties of transaction costs measurement.

\section{Difficulties of Transaction Costs Measurement}

Measuring about transaction costs has been a burning question since it appears. However, the measuring works face numerous difficulties. First, as written above, there is no standard terminology about the definition of transaction costs (Alexandra Behnam \& Lee Behnam, 2001). So it is too hard to identify what transaction should be considered, what costs or expense should be regarded as transaction costs. Second, it's unobservable that costs appear in the shape of non-market value. Because of different culture and customs, the behaviors in transaction lead to different transaction costs, they're too difficult to be calculated numerically (Liu \& Shen, 2006). Thirdly, opportunity cost can't replace the transaction costs. The principals conducted in transaction are just a little portion of numerous transaction behaviors (Alexandra Behnam \& Lee Behnam, 2001), and opportunity costs can just represent a part, but not all. It's also important for measuring transaction costs to analyze why the principal adapts one but not others.

On the perspective of contract signing and executing, R. C. O. Matthews (1986) presents the fundamental idea of transaction costs. He believes that transaction costs consist of the costs of arranging a contract before signing and monitoring and enforcing it after signing, as opposed to production costs, which are the costs of executing the contract. We considered that his narrow definition enables the measuring of transaction costs. That is the work of measuring could be preceded around the contract. For the contract arranging, executing, monitoring and enforcing, one could measure the transaction costs in different stages separately. So we consider Matthews' definition is supportable and reasonable for measuring.

\section{Methods of Transaction Costs Measurement}

Available researches all divide the measurement into macro aspect and micro aspect, on the macro aspect it refers measuring the costs of economics system operation or institution transformation, on the micro aspect, and it refers measuring the costs of some industry or field executing a transaction (Zhang 2010). So, we should also consider the meaning of transaction costs on two aspects. According to Steven N.S. Cheung (1998), the measurement includes accurate measuring and margin contrast analysis. The former means adopting statistics data or model to calculating the costs, and the latter means non-accurate but comparable analysis. If we are able to say ceteris paribus, that's a particular type of transaction cost is higher in Situation A than in Situation B, and that different individuals consistently specify the same ranking whenever the two situations are observed, it would follow that transaction costs are measurable, at least at the margin (Cheung, 1998).

\subsection{On the Macro Aspect}

Most of the works on macro aspect are concentrated on the measuring economy transaction costs and studying interaction between transaction costs and economic growth. The methods are widely adopted. One is directly measuring, just as Wallis \&North have done in 1986. They partition the nation economic sections. The other is to build measuring model referred to Wallis \&North's direct measuring method. In addition, researches based on the view of institution evolution also constitute a potential direction of studying. 


\subsubsection{Direct Measurement}

Scholars conduct direct measurements referring to Wallis \&North's method. First, they partition the economic as national economics sections, transaction section, actions of economic principals. Then, use indexes such as employee compensation, industry growth, GNP or GDP to calculate costs (Wallis \&North, 1986; Liu \& Shen, 2006). Wallis \& North's work is groundbreaking that they put forward the idea of partitioning the economy section which provides the basic idea of measuring. Yet, what's the imperfect is they simply added the calculable value in the market but couldn't consider about the transaction costs which didn't appear as market price, it is reasonable that separated the social operation costs into transaction costs and transfer costs, but difficult to implement (Li \& Zhong, 2008). The research work of transaction costs shouldn't be divided off social economic system which Wallis \&North haven't deeply analyzed it. Scholars have improved the methodology according to Wallis \&North's theory. In China, Miao \& Chen (2002) have adapted the method of Wallis \&North to measure the transaction costs of national economic from 1978 to 2000. They also proposed the macroeconomic frame of transaction costs measurement. Enterprise should be regarded as basic surface when measuring transaction costs, and at the same measuring the transaction costs inside and outside of it. All in all, we can see that the surface of enterprise links the macro aspect together to the micro aspect in the figure1.

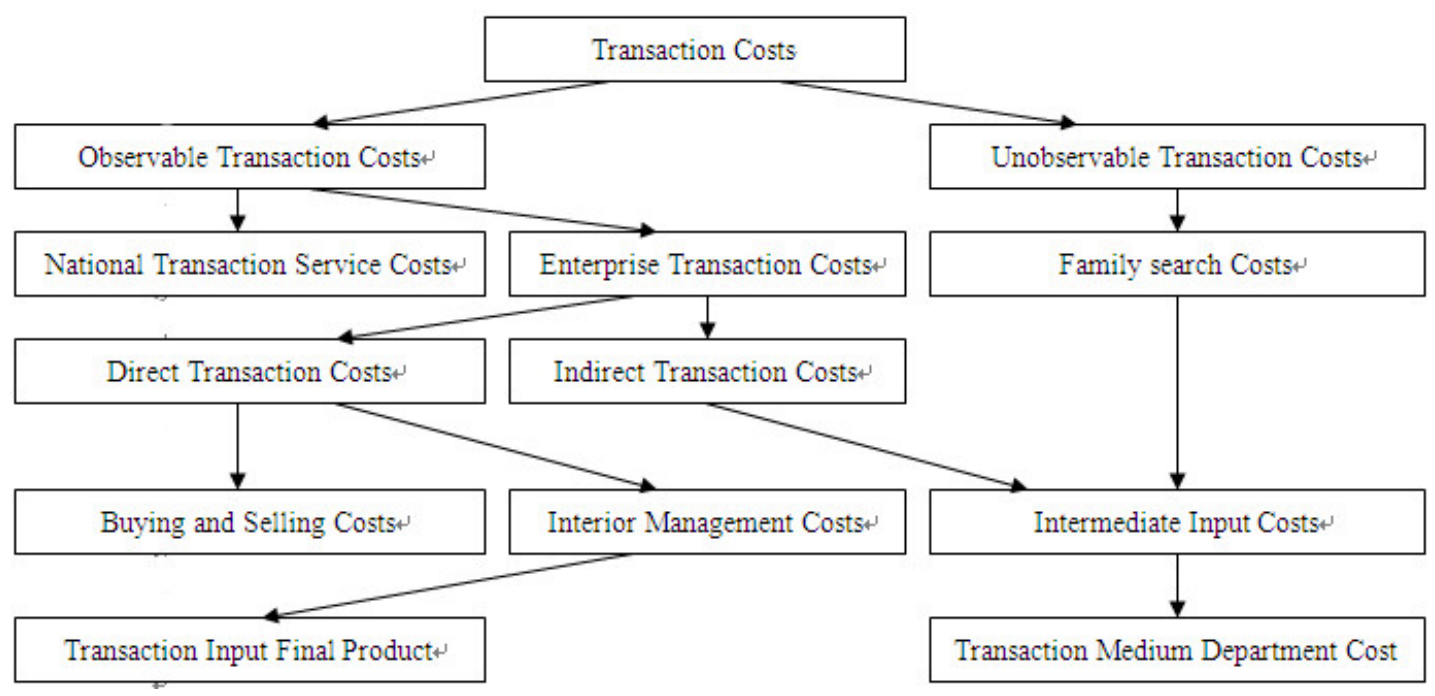

Figure1. The frame of transaction cost measurement

Data source: Miao \& Chen, 2002, China Measuring of Transaction Costs and Economy Growth

Qiu \& Huo (2007) have made a dynamic analysis on China's transformation period transaction costs. That research has proposed the concept of transaction business and non-transaction business, which perfected the method of industry partition for transaction costs measurement. What's more, the research have complemented the Wallis \&North's method and discovered that the transaction costs of transformation period in China are more explicit. Its significance is that it has discovered the unobservable transaction costs and studied the change of transaction costs interior structure, which is helpful for us to find out what transaction should exist, what transaction should abolish, and find out new economy growth point. Da \& Zhang (2009a) have conducted a research on the industrial transaction costs from 1978 to 2007. In that paper, They have calculated tertiary industry transaction costs, and deemed that public sections transaction costs is represented by public sections added value, while non-trading sections transaction costs is represented by half of employee' whole salary.

\subsubsection{Building Measurement Model}

The popular measuring model is SEM (Structural Equation Model). Da \& Zhang (2009b) have built a model of MIMIC (Multiple Indicators and Multiple Causes) upon SEM and measured the scale of non-market transaction ever since China reform and opening up to the outside world. That research has made up the defect of Wallis \& North's method_ _ ignoring the non-market transaction. Zhang (2010) has established satellite account of the system of SNA (System of National Accounts). In this system, the transaction costs are important indicators when evaluating national economy like GDP and CPI (Zhang, 2010). The total national transaction costs are consisted of transfer sections costs, trading sections costs and public sections costs. Whereas, how to distinguish the three departments has been a difficult and subtle problem, as one transaction costs may be repetitive accounted in different sections. 


\subsubsection{Institution Evolution Margin Analysis}

Based on the perspective of comparative institution, Pi \& Xiong (2011) have analyzed the Xiaogang village's development and institution evolution. In that paper, they have proposed that the view of transaction costs should include expectation transaction costs. And they also believe that measurement should not only model and number, but the method of margin analysis should be adopted, too. According to Steven Cheung's perspective (1998), both gross and transaction efficiency should be considered when measuring. The significance of margin analysis is that the institution is to save the transaction costs, but the number it saved can't be calculated. On the perspective of margin analysis, it will be a theatrical support if we could estimate the increase or decrease of the costs.

\subsection{On the Micro Aspect}

\subsubsection{Buy-Sell Price Margin Method}

Wang N (2003) has introduced a method that is measuring the margin of buy-sell price in transaction. In Robert N. Stavins' paper (1995), it has been measured according to the buying-selling price in the market of $\mathrm{SO}_{2}$ permits. This method has provided the measuring of enterprise aspect. It is helpful for an enterprise to choose the pattern of operating and profit, but it hasn't included the costs of monitoring, enforcing and time.

\subsubsection{Typical Reference Quantities Method}

Jeffery, H. Dyer \& Wujin Chu (2003) have used time of consumption between supplier and manufacturer in price negotiation, bargaining, signing a contract and solving problems, and conversing into transaction costs to work out a formula. The formula was used in that paper as equation (1). Because of difficult to measure, this method offers a new thinking idea. Selecting typical reference quantities such as time, price, transaction population number, and unity them into the same unit. The key point of this method is to find out the easy available or to switch quantities among numerous indicates. We consider that this method is fit for two kind of transaction comparative research, but too difficult to analyze the whole costs.

$$
\begin{aligned}
& \text { Ex ante transaction costs (ExanteTC) } \\
& =(\text { total annual person days of face to face time spent }) \\
& \times(\text { percent of time spent on price negotiation / contracting }) \\
& \div(\text { supplier sales to the buyer })
\end{aligned}
$$

\subsubsection{Iinvestigating Method}

A model for calculating the GSM transaction costs has been built in an econometric method. The study has found that GSM business can reduce production cost of doing business in terms of traveling and transaction costs (Bakare \& Lola, 2011). In this paper, 1000 questionnaires have been made in the Ilorin's 20 communities in Kwara State, Nigeria. The model as equation (2) is a powerful tool for transaction costs measurement.

$$
\begin{aligned}
& \text { TRCOSTij }=\lambda_{0 j}+\lambda_{1 j} N_{S S R_{j}}+\lambda_{2 j} H H A_{j}+\lambda_{3 j} G S M E P_{j}+\lambda_{4 j} C W E L_{j}+\lambda_{5 j} G S M T A_{j} \\
& +\lambda_{6 j} D D B_{j}+\lambda_{j j} A B I_{j}+\lambda_{8 j} E D U C_{j}+\lambda_{9 j} G S M T T C_{j}+\lambda_{10 j} P R E S T_{j}+\lambda_{1 j} S E X_{j}+\lambda_{12 j} S C A_{j}+e_{j} \\
& \lambda_{3 j}, \lambda_{4 j}, \lambda_{5 j}, \lambda_{6 j}, \lambda_{9 j},>0 ; \lambda_{i j}, \lambda_{8 j}, \lambda_{10 j}, \lambda_{12 j},<0 ; \lambda_{1 j}, \lambda_{2 j}, \lambda_{11},= \pm
\end{aligned}
$$

In equation (2) many factors even dummy variable have been applied, such as gender and reputation. We consider it has improved the accuracy. On the micro aspect, the method of econometric may be concise and practical. Not only can the transaction costs be figured out, but also the variables which and how affect can be observed. This plays a significant role in the research of industry development and planning.

\subsubsection{Data Statistics Method}

Many scholars directly use government statistics data or field survey statistics to conduct research although this way needed to cost a large number of manpower, material resources and time, but it contributes to remarkable and persuasive achievement. Government institutions documents researching can be regarded as a means of measuring public policy transaction costs. Katherine Falconer \& Caroline Saunders (2002) have studied communication, documents, contract agreement, telephone, conference, web access and other information from the government departments. They have estimated the transaction costs of agricultural environment management agreement negotiation process. Kuperan, Nik, Robert, Genio \& Salamance (2008) have studied the transaction costs of the Philippines San Salvador Island under two fishing models_ common management and centralized management, according to the data from 1988-1996. According to Kuperan et al's research, we learn that different transaction costs of various aspects management models should also be compared. Although different 
institutions are arranged, it is still not sure that transferring institution can reduce the transaction costs internal.

\section{Conclusions}

Although the measuring of transaction costs has certain framework and method, but the precise measuring for non-market transaction costs is still rare, because a non-market transaction cost is unobservable, it still stays on the experience research aspect (Liu \& Shen, 2006). And this transaction cost remains to be discovered. The accurate measuring of transaction costs faces many difficulties. For macroscopic aspects, there exist evolutions of economic system, development of culture, fusion of industry, change of institution, etc. For microscopic aspects, there exist data collection difficulties, trifling of information, data conversion between different units, etc. Therefore, we consider that margin comparison method should be a very good researching field, because it supplies non-accurate calculator question another way. For the macroscopic aspect of transaction costs measurement, we can do researches along the previous framework (Miao \& Chen, 2002): dividing transaction costs into two parts, observable and unobservable, and regarding enterprises as boundary. In a word, Researches on the interactions between different institutions arrangement and economic development should be the focus of scholars, which will contribute to the transformation of national economy, the formulation of national policy, legislation and institution.

\section{Acknowledgements}

This paper is supported by the National Natural Science Foundation of China (Project Number 71003070), Innovation Program of Shanghai Municipal Education Commission (Project Number 10YS106), Shanghai Leading Academic Discipline Project (Project Number J50504) and Shanghai Municipal Education Commission Major Course Construction (Industrial Economics). Authors express their gratitude to them sincerely. We also thank editors and reviewers for their sincere advice and comments.

\section{References}

Benham, A., \& Benham, L. (2003). Institution, Contract and Organization. Peking: Economic Science Press.

Benham, A., \& Benham, L. (2001). The Costs of Exchange. Ronald Coase Institute Working Paper Series, Number 1, July.

Bakare, A. S., \& Gold, K. L. (2011). Estimating the Impacts of Global System for Mobile Telecommunication (GSM) on Income, Employment and Transaction Cost in Nigeria. Journal of Economics and International Finance, 3, 37-45.

Da, F., \& Zhang, W. (2009a). Trade Transformation and Calculation of the Three Industry under the Background of Social Division and Specialization: from 1978 to 2007. Reform, 9, 52-57.

Da, F., \& Zhang, W. (2009b). The Non-market Transaction Costs Change and Estimation in China from 1978 to 2007: An Indirect An Indirect Measurement Based on the MIMIC Model. The Journal of Quantitative \& Technical Economics, 8,123-134.

Dyer, J.H., \& Chu,W. (2003). The Role of Trustworthiness in Reducing Transaction Costs and Improving Performance: Empirical Evidence from the United States, Japan and Korea. Organization Science, 14, 57-68. http://dx.doi.org/10.1287/orsc.14.1.57.12806

Wallis, J. J., \& North, D. C. (1986). Measuring the Transaction Sector in the American Economy, 1870-1970, Long-Term Factors in American Economic Growth. University of Chicago Press.

Commos, J.R. (1931). Instantiation Economics. Peking: The Commercial Press.

Falconer, K., \& Saunders, C. (2002). Transaction Costs for SSSIs and Policy Design. Land Use Policy, 19, 157-166. http://dx.doi.org/10.1016/S0264-8377(02)00007-8

Kuperan, K., Abdullah, N. M. R., Pomeroy, R. S., Genio, E.L., \& Salamanca, A.M. (2008). Measuring Transaction Costs of Fisheries Co-management. Coastal Management, 36, 225-240. http://dx.doi.org/10.1080/08920750701681991

Li, Y., \& Zhong, M. (2008). Transaction Cost Measurement Research. Market Modernization, 10, 162-163.

Liu, Z., \& Shen, J. (2006). Measuring Transaction Costs: Theoretic Development and Application. Finance \& Trade Economic, 10, 77-82.

Matthews, R. C. O. (1986). The Economics of Institutions and the Sources of Growth. The Economic Journal, 96, 903-918. http://dx.doi.org/10.2307/2233164 
Miao, R., \& Chen, Z. (2002). China Measuring of Transaction Costs and Economy Growth. Statistical Research, $8,14-21$.

Williamson, O.E. (1981). The Economics of Organization: The Transaction Cost Approach. The American Journal of Sociology, 87, 548-577. http://dx.doi.org/10.1086/227496

Pi, X., \& Xiong, D. (2011). Economic Analysis on Rural Property Rights Institution Change: Reconsideration of the Costs of Transaction Measurement Problem. Commercial Times, 30, 81-82.

Qiu, H., \& Huo, Q. (2007). The Transaction Costs Estimates Based on China Population Census Data. Modern Business, 6, 108-109.

Stavins, R. N. (1995). Transaction Costs and Tradable Permits. Journal of Environmental Economics and Management, 29,133-148. http://dx.doi.org/10.1006/jeem.1995.1036

Coase, R.H. (1937). The Nature of the Firm. Economic, 4, 386-405.

Coase, R.H. (1960). The Problem of Social Cost. Journal of Law and Economics.

Cheung, N. S. S. (1998). The Transaction Costs: 1998 Presidential Address Western Economic Association. Economic Inquiry, 36, 514-521. http://dx.doi.org/10.1111/j.1465-7295.1998.tb01733.x

Wang, N. (2003). Measuring Transaction Costs: An Incomplete Survey. Ronald Coase Institute Working Paper Series, Number 2, February.

Zhang, X. (2010). Macro-Accounting and Analysis of Transaction Costs Based SNA. Shandong Economic University Master's thesis. 